\title{
Towards an understanding of age-related macular disease
}

\author{
Eye (2003) 17, 457-466. doi:10.1038/ \\ sj.eye. 6700562
}

I am very pleased and honoured to be asked to give this lecture in memory of Sir William Bowman who as a clinician had considerable expertise in research techniques. After his medical training, he undertook extensive research in anatomy and became a talented microscopist before entering ophthalmology. $\mathrm{He}$ was elected FRS for his work on muscle at the early age of 25 years. Despite his expertise in the laboratory, he maintained throughout his life that the greatest lessons were to be gained from the (clinical) study of the diseases.

Bowman was well known internationally. It was he who introduced Donders to von Graefe when they both visited London for the Great Exhibition of 1851. Donders recorded that they met and had breakfast together after which they spent the rest of the day at Moorfields Eye Hospital; he writes that he left the hospital exhausted. The three were to remain close friends for the rest of their lives visiting each other frequently. They represented an ideal mix of talents, Donders with his expertise in physiology (he later became professor of physiology at Utrecht), von Graefe with his clinical experience, and Bowman the anatomist and microscopist. It is probably from this time that ophthalmology was established as the speciality that we know it today.

Although Bowman's main interests did not reside in the study of retinal diseases, had he been alive today undoubtedly he would have seen age-related disease (AMD) as a major challenge to ophthalmology. Its importance cannot be overemphasised. It accounts for about $50 \%$ of registered blindness in the Western world. ${ }^{1-6}$ The prevalence appears to be increasing at a rate not fully explained by the ageing population, ${ }^{7}$ and furthermore it appears to be occurring at an earlier age in that AMD is now recorded to be as common now as diabetes and glaucoma as a cause of visual loss during
AC Bird

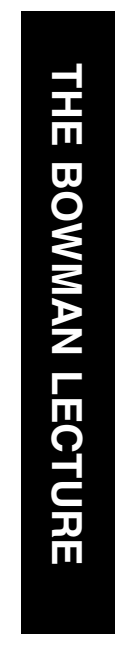

working life (16-65 years) in England and Wales. ${ }^{3}$ AMD is also the only major cause for registration that has increased in prevalence over the last decade. This in part reflects an ageing population, and better treatment of other sight-threatening conditions.

Despite the many controlled therapeutic trials over the last 25 years, ${ }^{8-20}$ there is no treatment to date by which the impact of blindness from AMD in the community will be influenced. It is accepted that AMD represents a major and growing pubic health problem in Western Europe and North America for which no remedy exists. Until recently, there has been little research seeking the basic cause and pathogenetic mechanisms of disease. Investigative activity and research monies have been largely devoted to controlled trials, which in retrospect is unfortunate. In the last decade, a research-concerted effort to address these problems has emerged, and it is hoped that this will give rise to novel therapeutic approaches or a better understanding of disease. In this paper, I will try to summarise the current state of research into the pathogenesis of AMD. In preparing this talk, I realise my indebtedness to my colleagues at The Institute of Ophthalmology, and Moorfields Eye Hospital and the many fellows, both from the UK and abroad who have worked in the medical retinal service over the last three decades.

\section{Risk factors in AMD}

It is widely believed that AMD occurs in those with genetic predisposition, and the disorder becomes manifest in the presence of environmental pressures. Considerable evidence exists to support the genetic influence of risk. The familial nature of AMD has long been suspected, although proof of this is relatively recent. There is now good evidence of genetic predisposition in AMD derived from observations of close concordance between monozygotic twins and greater concordance
Institute of Ophthalmology Moorfields Eye Hospital London, UK

Correspondence: Professor AC Bird Institute of Ophthalmology Moorfields Eye Hospital

City Road London ECIV 2PD, UK Tel: + 442072533411 ext 2257

Fax: + 442072519350

E-mail: Alan.Bird@

ucl.ac.uk 
between siblings than between spouses. ${ }^{21-25}$ Furthermore, the phenotype of early AMD appears to reflect the genetic influences since there is significant similarity of drusen number, size, and distribution between siblings. ${ }^{21}$ That the form of late AMD may also reflect the influence of the specific genes involved is suspected but unproven. It is likely that more than one gene is involved although the number has been considered small. ${ }^{22}$ In these respects, AMD is similar to other complex traits. ${ }^{26}$ It follows that ageing at the macula would vary qualitatively within a community. The high prevalence of clinically detectable early AMD in those over the age of 65 years (35-40\%) in industrial Western societies ${ }^{3-7}$ implies that the causative genetic variants are common in these populations.

Low prevalence of AMD in some non-Caucasian races has been well documented in the past, ${ }^{27,28}$ and it has been considered that this might indicate the lack of genetic risk factors. However, the disorder has become common in the last two decades in urban communities in Japan, ${ }^{29-32}$ and over the last 3 years the rate of hospital referrals has doubled (M Uyama, personal communication). Publications imply that a similar change in prevalence may be occurring elsewhere in East Asia. ${ }^{33-35}$ There is also a strikingly high prevalence of macular disease in elderly Inuit in Greenland. ${ }^{36,37}$

The common phenotypes are different in different communities. In Japan, detachment of the retinal pigment epithelium (RPE) and major haemorrhage are very common. Drusen in the fellow eye in those with unilateral visual loss are uncommon, although this eye is at risk of visual loss. In Greenland, the most common presentation is atrophy, and exudative lesions are very rare. Even in communities of Western European origin, the common phenotype of late disease appears to differ, geographic atrophy (GA) being the most common in Iceland, ${ }^{38}$ whereas choroidal neovascularisation (CNV) is most common elsewhere in Europe and North America. ${ }^{39}$ The variation may reflect differences in genetic risk factors or environmental pressures.

\section{Genetic studies}

Determination of the genetic risk factors would be a major advance in the understanding of the disease processes that initiate the disease, and may give rise to novel therapies. Finding good candidate genes would help considerably in this quest. These may be established by the identification of associated risk factors, of monogenic diseases that manifest some components of AMD, or by the study of the disease itself.

\section{Associated characteristics}

There have been several studies that have sought association between iris colour, which have given mixed results. ${ }^{40-42}$ One of the most recent studies implied that eye colour in youth had little influence of risk of AMD, but loss of iris melanin with age was a strong risk factor, there being an odds ratio of 9 between those that have dark irides that become lighter when compared with those in whom the irides remained dark with age. ${ }^{43}$ The significance of this association is unknown. Although premature greying of hair is recognised as being familial, and it is known that this may accompany generalised loss of melanin reflected in loss of tanning in sunlight, no genetic studies have been undertaken into this phenomenon.

\section{Monogenic diseases}

Several monogenic diseases have phenotypic similarity to AMD, Sorsby Fundus Dystrophy, and Doyne Honeycomb Dystrophy/ Mallatia Leventinese reproducing most closely the various components of disease. Best Disease, pattern dystrophies, fundus flavimaculatus, bull's eye maculopathy, North Carolina Macular Dystrophy, Stargardt Disease, and retinopathy caused by mutation in transcription factors, all have phenotypic similarity with AMD and the gene responsible for disease are known for each. None of these genes has been shown beyond doubt to play a pathogenetic role in AMD, but none has been excluded since in only ABCA4 is the study large enough to draw any definitive conclusion. Apolipoprotein- $\varepsilon 4$ has been shown to be protective. ${ }^{44,45}$ The protein expresses in Bruch's membrane, although the physiological role of apolipoproteins is unknown.

\section{Study of the disease}

Bowman would have seen the study of those changes precipitation disease as a very important exercise. Various histological studies have been undertaken, ${ }^{46-48}$ notably by Sarks and co-workers in which much of the phenomenology was described and more recently quantitative studies have been undertaken. The most recent was by Okubo et $a l^{49}$ and the significance of these will be discussed.

\section{Retinal pigment epithelium}

Accumulation of residual bodies that fluoresce can be used as an index of ageing in the RPE and was measured by Okubo in a series of donor eyes. The quantity is related to the balance of accumulation, which is the 
results of metabolic activity that in turn is driven by the need for photoreceptor outer segment renewal, and clearance that may be because of intracellular degradation or extrusion from the cell either inwards or outwards. Both residual body quantity as measured by electron microscopy and autofluorescence as seen by light microscopy had a quadratic relation with age. ${ }^{49}$ This was to be expected since the population of photoreceptors falls in the elderly. ${ }^{50}$ However, the relation between age and autofluorescence was not close, the adjusted $R^{2}$ being only 0.45 and for residual bodies the $R^{2}$ was 0.50 . This was because of the wide variation in the eyes from elderly donors. Thus, $50 \%$ of the variation in either autofluorescence or residual bodies is not explained by ageing; the suspicion is that genetic or environmental factors would play a role in determining the variance. Most surprising was the relation between autofluorescence and residual body volume. This was linear, which would have been expected since it is from the residual bodies that the autofluorescence is derived. However, the $R^{2}$ was only 0.26 . In retrospect, the variation between specimens should not be surprising since only a small proportion of the material in residual bodies fluoresces, and this proportion may be influenced by circumstances such as vitamin A content in diet. ${ }^{51}$

The clinical relevance of these finding is underlined by the ability now to image RPE autofluorescence in vivo through the efforts of Fitzke and von Rückmann. ${ }^{52}$ The evidence that the signal originates from lipofuscin in the RPE is derived from the work of Delori et al. ${ }^{53}$ Recently, it has been shown that in early ARM the distribution of autofluorescence varies from one patient to another. In about half it is homogeneous, whereas in the remainder it is diffusely irregular or focally increased autofluorescence is seen. ${ }^{54}$ Drusen do not appear to explain the differences, since apart from sero-granular drusen at the fovea, they do not autofluoresce significantly. It has been shown that in bilateral early ARM, the pattern is symmetrical implying that the pattern reflects the form of disease in an individual, and may be determined by the genetic or environmental influences. In unilateral disease, irregular autofluorescence is associated with GA in the other eye, and predicts GA in the good eye.

The last observation can be explained on the basis of further work by Okubo et al. ${ }^{55}$ Sprague-Dawley rats, 11 weeks-old, were injected with $5 \mu \mathrm{l}$ of a lysosomal protease inhibitor, E-64 $(2.22 \mu \mathrm{M})$, intravitreally once and killed at $24,48 \mathrm{~h}$, or 7 days. Others received two or three injections at $48 \mathrm{~h}$ intervals, and killed at 1, 4, and 7 days after the last injection. Eyes were enucleated and retinal tissues were processed for light and electron microscopy. A single injection of E-64 caused only a transient accumulation of phagosome-like and phagolysosome- like inclusion bodies in the RPE. In contrast, repeated injection caused progressive accumulation of these inclusions followed by changes in intracellular organelles such as loss of smooth endoplasmic reticulum and RPE cell conformation. This was accompanied by shortening and loss of photoreceptor outer segments (OS) without prior dysmorphic changes, photoreceptor loss, alteration of choroidal capillaries, and invasion of Bruch's membrane by fibroblasts and pericytes. Intravitreal injection of vehicle for comparison induced no structural changes.

It was considered likely that the shortening and loss of the OS was caused by impaired morphogenesis of disc membranes rather than degeneration, because photoreceptor cell OS showed no degenerative changes such as vesiculation of disc membranes. It was considered most likely that the shortening of the OS reflected the inability of the RPE to recycle materials due to either reduced phagosomal degradation or compromised lipid metabolism. The findings imply greater dependence upon the availability of products of phagosomal degradation for OS renewal than was previously evident and that acquisition of plasmaderived material is insufficient to sustain this process fully. The ability of the RPE to recycle lipids has been well illustrated. ${ }^{56,57}$ The observed changes are similar in some respects to age changes in RPE, photoreceptor and choroid, although it was freely acknowledged that there are major differences between such an acute experiment, and the consequences of life-long metabolic activity, and species differences between rat and human. However, this model may illustrate potential pathogenetic mechanisms of GA and explain the association of GA with focal increased autofluorescence if the latter is witness to the inability to recycle phagosomal contents.

\section{Bruch's membrane}

As have others, Okubo et al showed a linear relation between ageing and thickness of Bruch's membrane both by electron and light microscopy, ${ }^{49}$ but the $R^{2}$ were only 0.57 and 0.32 , respectively, with great variation in the elderly. This implies that factors other than ageing are important in influencing the magnitude of age-change.

The chemical constitution of Bruch's membrane has also been shown to be important in determining the influence of ageing. This was triggered by re-examining the pathogenesis of retinal pigment epithelial detachments in which it was proposed that the subpigment epithelial fluid is derived from the RPE rather than from the choroid. ${ }^{58}$ It is widely accepted that fluid is moved from the retina to Bruch's membrane because of active movement of ions by the RPE cells. ${ }^{59}$ If Bruch's membrane were to become hydrophobic, 
a significant resistance to water flow may be generated at this level causing fluid to collect between the RPE and Bruch's membrane. Such a mechanism demands that there be progressive accumulation of lipids in Bruch's membrane, and that this would vary from one patient to another. This explanation for the pathogenesis of retinal pigment epithelial detachments had the attraction over previous concepts in that it was compatible with the observed behavioural characteristics of RPE detachments. Support for this concept is derived from both histopathological, biochemical, biophysical and clinical observations.

A study of frozen tissue undertaken using histochemical staining techniques on human eyes with an age range between 1 and 95 years ${ }^{60}$ showed accumulation of lipids with age that varied both in the quantity and form of lipids. Some eyes stained for neutral lipids alone, some stained predominantly for phospholipids, and others stained equally for both neutral lipids and phospholipids. To confirm these conclusions, material extracted by lipid solvents from tissue of eye-bank fresh eyes has been analysed by thin layer and subsequently gas chromatography. ${ }^{61}$ After separation, the chemical species were identified by mass spectroscopy. This study confirmed the conclusion that the quantity of lipid in Bruch's membrane increases with age. Eyes from donors over the age of 60 years showed wide variation of total lipid extracted from donors of similar age that the ratios of phospholipids to neutral fats was different from one specimen to another from donors of similar age.

Finally, measurements of hydraulic conductivity of Bruch's membrane showed that it becomes reduced with age $^{62,63}$ and, after the age of 50 years, there is a close linear relation between conductivity and lipid content.

The finding that the major lipid species were phospholipids and fatty acids rather than cholesterol and cholesterol esters ${ }^{54}$ implied that the lipids were of cellular (presumably RPE), rather than plasma in origin.

Clinical support was sought to support the concept that the biochemical content as well as the thickness of Bruch's membrane influenced subsequent clinical behaviour. It has been hypothesised that drusen that are hyperfluorescent on fluorescein angiography must be hydrophilic allowing free diffusion of water-soluble sodium fluorescein into the abnormal deposit and that there would be binding of sodium fluorescein to polar molecules; in contrast if the drusen were hypofluorescence it would imply that they are hydrophobic because of the presence of neutral lipids. ${ }^{58}$ This conclusion was supported by histological observations in which it was shown that the binding of sodium fluorescein correlated well with the biochemical contents of drusen. ${ }^{64}$ It would be predicted that the highest resistance to water flow in Bruch's membrane would be found in eyes destined to suffer tears of the detached RPE in which the concept implies that sufficient tangential stress is induced in the detached tissues to cause them to rupture. The determination that a tear in one eye implied high risk of a similar event occurring in the fellow eye ${ }^{65}$ provided the opportunity to test the concept. A comparison was made of the drusen in the fellow eye of a tear with those of a fellow eye of one with visual loss caused by subretinal neovascularisation. It was shown in two studies that the drusen were larger, more confluent, and less fluorescent on angiography in the former group than in the latter. ${ }^{66,67}$

Microscopic studies show that thickening of Bruch's membrane may be in the form of discrete deposits on its inner surface, or diffuse (linear) accumulation that is seen as a continuous layer in the inner or outer portion of Bruch's membrane. Clinical studies have been directed towards the analysis of discrete deposits on the inner surface of Bruch's membrane that can be recognised clinically as drusen. However, they have largely ignored the potential importance of diffuse Bruch's membrane thickening because of the lack of any recognised clinical manifestations of linear change. Logically, the diffuse deposits would be expected to play a major role in determining the outcome of disease.

As a result of studies on Sorsby fundus dystrophy, ${ }^{68-70}$ it was suggested that a prolonged choroidal filling phase on fluorescein angiography may be a clinical sign of diffuse thickening of Bruch's membrane. In this autosomal dominant condition, a continuous layer of abnormal material of up to $30 \mu \mathrm{m}$ in thickness is deposited between the inner collagenous layer of Bruch's membrane and the basement membrane of the RPE. ${ }^{71}$ In contrast with the normal rapid filling, a contiguous area of prolonged, patchy choroidal fluorescence is seen during the transit phase of fluorescein angiography. ${ }^{68-70}$ The dye appears initially in the inner choroid as small points of fluorescence that gradually enlarge and coalesce with one another over several frames of the angiogram. Continuous fluorescence indistinguishable from the surrounding normal fundus is not apparent until the late venous phase of the retinal circulation. Fluorescein angiography transit photographs were analysed in the good eye of consecutive patients with unilateral visual loss from AMD. ${ }^{72}$ Of these, $26 \%$ had evidence of a prolonged choroidal filling phase during the initial dye transit. This angiographic sign could represent the clinical correlate of changes in the choriocapillaris as identified by microscopy. ${ }^{73-75}$

In order to establish the potential significance of this clinical sign, visual sensitivity was measured in eight eyes with this angiographic finding, and in six eyes with similar amounts of drusen but normal choroidal filling. ${ }^{76}$ 
Scotopic threshold measured using the Humphrey automated perimeter and fine matrix mapping showed no discrete area of increased threshold when compared with the background sensitivity in eyes with normal choroidal perfusion. By contrast, in seven of the eight eyes with fluorescein angiographic evidence of prolonged choroidal filling, discrete areas of scotopic threshold elevation of up to $3.4 \mathrm{log}$ units were recorded, which corresponded closely to regions of choroidal perfusion abnormality. In addition, there was prolonged recovery from bleach in those field loci with normal dark-adapted sensitivity.

The visual acuity and the fundus appearance were identical in eyes with and without abnormal choroidal perfusion such that neither clinical attribute segregated these two populations. Although no simple clinical clues exist to identify those patients with loss of scotopic sensitivity and abnormal choroidal perfusion, functional correlates were evident to the patients. They report the need for increased light intensity for reading, fading vision after a few minutes in bright light, easy fatigability when doing close work and a central scotoma on waking at night.

No established pathogenetic concepts were readily available to explain either the changes in choroidal fluorescence on angiography or the functional loss. Diminution of the choroidal capillary bed with age had been shown by structural studies, and the absence of change in the arteries make it unlikely that it is because of arterial obstruction or systemic hypertension. ${ }^{77-79}$ There is circumstantial evidence that the behaviour characteristics of the choriocapillaris are determined by the $\mathrm{RPE}^{80}$ and it had been proposed that the diffusible agents from the pigment epithelium modulate the choroidal vasculature. ${ }^{81}$ Based on these hypotheses, it was proposed that a barrier to diffusion at the level of Bruch's membrane would result in changes in choroidal capillaries. If the normal characteristics of the choroidal capillaries are dependent upon the diffusible agent, failure of this agent to reach the choroid would result in the vessels reverting to the more common tubular arrangement of capillary beds.

A unifying mechanism was proposed by which these changes may be generated. A continuous layer of debris in Bruch's membrane may act as a barrier to metabolic exchange between the RPE and the choroidal capillaries. If this is the case, it could explain both the psychophysical and angiographic findings observed in this and other studies. Normal photoreceptor function is dependent on the free diffusion through Bruch's membrane of large molecule complexes as they pass from the choriocapillaris to the pigment epithelium. ${ }^{82}$ Predictably such molecules would not pass freely through a continuous layer of debris particularly if it were hydrophobic. The magnitude of change would depend upon the thickness and chemical composition of the material within Bruch's membrane; the disturbance would be particularly marked in the presence of a large quantity of neutral fats. This conclusion was supported by the reversal of visual deficit in Sorsby fundus dystrophy by dietary supplementation with highdose vitamin $\mathrm{A}_{1}^{83}$ and similar observations have been made in early AMD (personal observation). The surprise was that vitamin A alone was sufficient to reverse the functional abnormality. This implies that the RPE is less efficient in recycling vitamin A than other metabolites.

Considerable research has been undertaken concerning the relevance of changes in Bruch's membrane to CNV. It is believed that the failure of blood vessels to invade Bruch's membrane is related to the local environment being alien to neovascularisation because of the nature of Bruch's membrane and the presence of growth factors that suppress new vessel growth.

It has been suggested that neovascularisation may be caused by inflammatory or immune-mediated processes. Chronic inflammatory infiltrates have been demonstrated in the inner choroid in donor eyes. ${ }^{84,85}$ Proteins associated with immune-mediated disease appear to accumulate in large quantities, ${ }^{86,87}$ and transcripts that encode a number of these molecules have been detected in retinal, RPE, and choroidal cells. Dendritic cells, potent antigen-presenting cells, have been reported to be intimately associated with drusen development and that complement activation is a key pathway that is active both within drusen and along the RPE-choroid interface. Changes in the extracellular matrix of Bruch's membrane have been likened to atherosclerosis, ${ }^{88}$ in which inflammatory phenomena occur. 89,90

The potential role of growth factors has been subject of intense study. Pigment epithelial-derived growth (PEDF) factor appears to suppress neovascularisation, ${ }^{91,92}$ while other factors, notably vascular endothelial growth factor (VEGF), stimulate blood vessel growth.$^{93}$ Both are expressed in the outer retina. ${ }^{94,95}$ Imbalance between growth factors has been shown in retinal diseases characterised by new vessel growth, ${ }^{96,97}$ and increased VEGF expression has been shown in experimental $\mathrm{CNV}^{98}$ in human choroidal new vessel complexes. ${ }^{99,100}$

That the normal choriocapillaris possesses cellular intrusions into Bruch's membrane ${ }^{101-104}$ may be relevant to CNV. These are thought to add physical stability to the choroidal capillaries. It has been suggested that CNV may be a distortion of this normal phenomenon, a concept supported by the observation that photocoagulation, which is known to distort growth factor expression, ${ }^{95}$ causes these to be larger and more numerous. ${ }^{105}$ 


\section{Correlation of RPE and Bruch's membrane changes}

Okubo et $a l^{49}$ also examined the relation between agechange in the two tissues. Not surprisingly, there was a linear relation between the two, since the deposits in Bruch's membrane are derived largely from the RPE. However, the $R^{2}$ was only 0.18 by light microscopy and 0.36 by electron microscopy with wide variation in the elderly. Thus, it would appear that a change in one tissue is not totally determined by changes in the other.

\section{Conclusions}

Study of the disease shows that ageing explains less than $50 \%$ of age-changes in subretinal structures in early AMD, and that a degree of independence exists between changes in the various tissues involved in the disease process. This should not have been surprising if variance of the numerous metabolic activities that might influence the magnitude of early age-changes is taken into account. These activities would include the speed of outer segment renewal, RPE degradative activity, free radical scavenging activity, RPE recycling ability, the efficiency of RPE cytoplasmic renewal, the speed of clearance of Bruch's membrane, and the response to age-change. Each of these is likely to be under genetic control and various genes might be involved in each. Thus, study of the disease does not serve to limit greatly the number of genes that might be involved in conferring risk of AMD.

These studies have generated concepts that represent potential explanations as to the pathogenesis of lesions of late AMD that cause loss of central vision.

\section{Future research}

The state of knowledge allows future research to be planned seeking the basic disease mechanisms, and determinants of risk in AMD.

\section{Genetic}

AMD is a complex disorder, and techniques have been generated to investigate other complex disorders such as multiple sclerosis, bipolar disease, schizophrenia, breast cancer, and diabetes. ${ }^{106}$ AMD is likely to share many of the problems involved in each such as the number of genes involved, but in AMD the prevalence of genetic variants conferring risk in the population may be high so that it cannot be assumed that there is a single genetic risk factor in a family. The one advantage that exists in AMD is that it lends itself to phenotyping, and that there is evidence that the phenotypic variants reflect the genes conferring risk in a family at least with respect to the size, density, and size of drusen. It is also possible that other features of disease such as the presence or absence of peripheral reticular change, distribution autofluorescence in early AMD, fluorescence of drusen on fluorescein angiography, and the lesion causing visual loss may also have similar significance. The symmetry of phenotype between eyes with AMD, both early and late, ${ }^{107,108}$ indicates that they reflect the nature of risk factors in an individual whether determined by the genes involved or their environment. The ability to achieve purer sample of disease may be crucial to the genetic study of AMD. It is clear that large numbers of DNA samples will be needed. Thus, DNA collections should be collected from large numbers of patients with wellcharacterised disease. The ideal comparison group would be spouse of patients since this would control to some extent for variation in environment assuming that spouses share a common way of life. Collections should be made in different communities since it cannot be assumed that patients from different origins will share common genetic variants conferring risk. The recent experience concerning the genetic studies of the potential role of $\mathrm{ABCA} 4^{109-111}$ in the pathogenesis of AMD illustrate the difficulties of such studies and underlines the need for well-documented patient resources.

\section{Environment}

The apparent rise on prevalence of AMD in Western Society, the emergence of AMD in Caucasian communities in developing economies, and East Asia, all indicate that environment is likely to be important in the pathogenesis of disease. However, apart from smoking, studies have not identified consistently any factor that would explain the apparent strong association of AMD with the Western way of life. ${ }^{112-117}$ It appears that environment has not been proven beyond doubt to be important. This could be tested by cross-sectional studies of communities with similar genetic background but different lifestyles. Such circumstances exist. Selfsupporting and urban communities that are in close physical proximity still exist in parts of Europe. Similar studies could be undertaken comparing urban populations with fishing or agricultural communities in both Japan and the Chinese diaspora, or Iniut in Greenland and Northern Canada.

\section{Biochemistry and cell biology}

Both biochemists and cell biologists have contributed towards our understanding of potential disease mechanisms in AMD, although their entry into the field has been relatively recent.

That biochemical studies may be fruitful is indicated by success in the investigation of other complex 
disorders. Progress in the understanding of Alzheimer has been well summarised recently. ${ }^{118}$ It affects about $5 \%$ of the population of 60 years, the prevalence doubles with each decade, autosomal dominant disease is rare, the clinical definition is imprecise, and it affects females more often than males, attributes reminiscent of AMD. The diagnosis is confirmed by histopathological identification of amyloid plaques and neurofibrillary tangles, and that atrophy starts in hippocampus. The major breakthrough occurred by determining that the plaques were made up of amyloid $\beta(\mathrm{A} \beta)$ peptide- 42 , and this has sustained intense and highly successful research. $\mathrm{A} \beta$ peptides are formed by the cleavage of amyloid precursor protein by $\beta$-secretase and $\gamma$-secretase, and may be of 40 or 42 amino acids. The ratio in youth is $9: 1$ but increases to $8: 2$ in Alzheimer's disease (AD); $\mathrm{A} \beta-42$ increases diffusely in the brain and subsequently becomes sequestered as plaques. A $\beta-42$ polymerises but A $\beta$-40 does not, and copper and possibly zinc are involved in plaque formation.

This explained the distribution of plaques in early disease since neurones in the hippocampus derived from the epirhinal cortex have the highest expression of amyloid precursor protein. Most importantly, it led to the identification of mutations in AD in amyloid precursor protein. Mutations in presenilin 1 and 2 have also been identified in dominant disease; the precise function of these enzymes is unknown, but mutations in each increases the expression of $\mathrm{A} \beta-42$. These genes have yet to be shown to be involved in non-dominant AD. This work allowed animal models of AD to be generated, and treatment trials initiated. Therapeutic trials using vaccination against $\mathrm{A} \beta-42$, and chelation of copper have both caused resolution of plaques, although benefit to humans awaits completion of therapeutic trials.

It would be a huge advantage if a central biochemical theme were available to us in the investigation of AMD. The evidence that TIMP-3 plays an important role in the generation of AMD is as strong as that for $\mathrm{A} \beta-42$ in $\mathrm{AD}$. Dominant disease caused by mutations in the TIMP3 gene exists, ${ }^{119}$ and TIMP3 is the most common peptide species in Bruch's membrane and drusen with age. ${ }^{120}$

\section{Conclusions}

It is hoped that future investigative activity will give some clues as to the triggering mechanisms of disease, intermediate disease mechanisms and reasons for visual loss, and eventually new therapeutic approaches may emerge. The various studies have already revealed a great deal concerning relevant disease mechanisms involved in generating the changes in early AMD, and an explanation exists for the pathogenesis of the lesions of late disease. The current increasing pace of research augurs well for the future. It will involve cooperation between clinicians, experimental pathologists, cell biologists, biochemists, molecular geneticists, and epidemiologists.

I can think of no better to finish this address by quoting Bowman from his inaugural address to the Ophthalmic Society of the UK in 1881 that is totally appropriate to the current research efforts. When considering the past he states: 'The several sciences, handmaids of medicine, had opened various vistas of striking interest ... The clinical domain cultivated a truer insight into the nature of disease and the best methods of averting or of dealing with it.'

He then considered the future: 'We look eagerly forward towards the younger to instruct us in new paths and to be pioneers towards a brighter future.'

These sentiments transmit an aura of optimism that I believe justified, and hopefully, the challenge of AMD will attract many with the hope that in the future the prospects will appear brighter for the many who suffer from this disorder.

\section{References}

1 Grey RHB, Burns-Cox CJ, Hughes A. Blind and partially sighted registration in Avon. Br J Ophthalmol 1989; 73 : 988-994.

2 Thompson JR, Rosenthal AR. Recent trends in the registration of blindness and partial sight in Leicester. $\mathrm{Br} J$ Ophthalmol 1989; 73: 95-99.

3 Evans J. Causes of blindness and partial sight in England and Wales 1990-1991. Studies on Medical and Population Subjects, No. 57. Her Majesty's Stationary Office: London, 1995.

4 Klein R, Klein BEK, Linton KLP. Prevalence of age-related maculopathy. The Beaver-Dam Eye Study. Ophthalmology 1992; 99: 933-943.

5 Mitchell P, Smith W, Attebo K, Wang JJ. Prevalence of agerelated maculopathy in Australia. The Blue Mountains Eye Study. Ophthalmology 1995; 102: 1450-1460.

6 Vingerling JR, Dielemans I, Hofman A, Grobbee DE, Hijmering M, Kramer CF et al. The prevalence of agerelated maculopathy in the Rotterdam Study. Ophthalmology 1995; 102: 205-210.

7 Evans J, Wormald R. Is the incidence of registrable agerelated macular degeneration increasing? Br J Ophthalmol 1995; 79: 9-14.

8 Macular Photocoagulation Group. Argon laser photocoagulation for senile macular degeneration: results of a randomised clinical trial. Arch Ophthalmol 1982; 100: 1347-1357.

9 Coscas G, Soubranne G. Photocoagulation des néovaisaux sourétiens dans le dégénérescence maculaire sénile par laser á argon: résultas d'une édute randomisée de 60 cas. Bull Mem Soc Fr Ophtalmol 1982; 88: 102-106.

10 Moorfields Macular Study Group. Treatment of senile macular degeneration; a single blind randomised trial by argon laser photocoagulation. Br J Ophthalmol 1982; 66: 745-753. 
11 Moorfields Macular Study Group. Retinal pigment epithelial detachments in the elderly: a controlled trial of argon laser photocoagulation. Br J Ophthalmol 1982; 66: 1-16.

12 Chisholm IH. The recurrence of neovascularisation and late failure in senile disciform lesions. Trans Ophthalmol Soc UK 1983; 103: 354-359.

13 Macular Photocoagulation Group. Argon laser photocoagulation for neovascular maculopathy: three year results for randomized clinical trials. Arch Ophthalmol 1986; 224: 493-501

14 Interferon Study Group. Interferon alfa-2a is ineffective for patients with choroidal neovascularization secondary to age-related macular degeneration: results of a prospective randomized placebo controlled clinical trial. Arch Ophthalmol 1997; 115: 865-872.

15 Hart PM, Chakravarthy U, MacKenzie G, Archer DB, Houston RF. Teletherapy for subfoveal choroidal neovascularisation of age-related macular degeneration: results of follow up in a non-randomised study. $\mathrm{Br} \mathrm{J}$ Ophthalmol 1996; 80: 1046-1050.

16 Chakravarthy U, MacKenzie G. External beam radiotherapy in exudative age-related macular degeneration: a pooled analysis of phase I data. Br J Radiol 2000; 73: 305-313.

17 Schmidt-Erfurth U, Miller J, Sickenberg M, Bunse A, Laqua $\mathrm{H}$, Gragoudas E et al. Photodynamic therapy of subfoveal choroidal neovascularization: clinical and angiographic examples. Graefes Arch Clin Exp Ophthalmol. 1998; 236: 365-374.

18 Treatment of Age-related Macular Degeneration with Photodynamic Therapy Group. Verteporfin therapy on subfoveal neovascularization in age-related macular degeneration. One year results of two randomized clinical trials. Arch Ophthalmol 1999; 117: 1329-1344.

19 Treatment of Age-related Macular Degeneration with Photodynamic Therapy Group. Verteporfin therapy of subfoveal choroidal neovascularization in age-related macular degeneration: two-year results of a randomized clinical trial including lesions with occult with no classic choroidal neovascularization - verteporfin in photodynamic therapy. Am J Ophthalmol 2001; 131: 541-560.

20 Treatment of Age-related Macular Degeneration with Photodynamic Therapy Group. Photodynamic therapy of subfoveal choroidal neovascularization in age-related macular degeneration with verteporfin: two-year results of 2 randomized clinical trials. Arch Ophthalmol 2001; 119: 198-207.

21 Piguet B, Wells JA, Palmvang IB, Wormald R, Chisholm IH, Bird AC. Age-related Bruch's membrane change: a clinical study of the relative role of heredity and environment. Br J Ophthalmol 1993; 77: 400-403.

22 Heiba IM, Elston RC, Klein BEK, Klein R. Sibling correlations and segregation analysis of age-related maculopathy: The Beaver Dam Eye Study. Genet Epidemiol 1994; 11: 51-67.

23 Silvestri TG, Johnson PB, Hughes AE. Is genetic predisposition an important risk factor in age-related macular disease? Eye 1994; 8: 564-568.

24 Klein ML, Mauldin WM, Stoumbos VD. Heredity and age-related macular degeneration. Observations in monozygotic twins. Arch Ophthalmol 1994; 112 : 932-937.

25 Gorin MB, Breitner JC, De Jong PT, Hageman GS, Klaver $\mathrm{CC}, \mathrm{Kuehn} \mathrm{MH}$ et al. The genetics of age-related macular degeneration. Mol Vis 1999; 5: 29.

26 Ott J. Complex traits on the map. Nature 1996; 379: 772-773.
27 Gregor Z, Joffe L. Senile macular changes in the black African. Br J Ophthalmol 1978; 62: 547-550.

28 Schachat AP, Hyman L, Leske MC, Connell AM, Wu SY. Features of age-related macular degeneration in a black population. Arch Ophthalmol 1995; 113: 728-735.

29 Kubo N, Ohno Y, Yanagawa H, Yuzawa M, Matsui M, Uyama M. Annual estimated number of patients with senile disciform macular degeneration in Japan. Research committee on Chorioretinal Degenerations. The Ministry of Health and Welfare of Japan, Japan, 1989, pp 136-139.

30 Kubo N, Ohno Y, Yuzawa M et al. Report on nationwide clinico-epidemiological survey of senile disciform macular degeneration in Japan. Research Committee on Chorioretinal Degenerations. The Ministry of Health and Welfare of Japan, 1990, pp 121-124.

31 Yuzawa M, Hagita K, Egawa T, Minato H, Matsui M. Macular lesions predisposing to senile disciform macular degeneration. Jpn J Ophthalmol 1991; 35: 87-95.

32 Maruo T, Ikebukuro N, Kawanabe K, Kubota N. Changes in causes of visual handicaps in Tokyo. Jpn J Ophthalmol 1991; 35: 268-272.

$33 \mathrm{Koh}$ AH, Ang CL. Age-related macular degeneration: what's new. Ann Acad Med Singapore 2002; 31: 339-404.

34 Yang CS, Lin CL, Lee FL, Tsai SC, Chung YM, Liu JH. Digital indocyanine green angiography in chorioretinal diseases. Chung Hua I Hsueh Tsa Chih Taipei 1995; 56: 411-417.

35 Chen SN, Liu KR, Tsai CB, Yang CH, Yang CM, Chen MS. Indocyanine green videoangiography of choroidal neovascular membrane in age-related macular degeneration. J Formos Med Assoc 1993; 92: 823-828.

36 Rosenberg T. Prevalence and causes of blindness in Greenland. Arct Med Res 1987; 46: 13-17.

37 Rosenberg T. Prevalence of blindness caused by senile macular degeneration in Greenland. Arct Med Res 1987; 46: 64-70.

38 Jonasson F, Arnarsson A, Sasaki H, Peto T, Sasaki K, Bird AC. The prevalence of age-related maculopathy in Iceland: Reykjavik eye study. Arch Ophthalmol 2003; 121: 379-385.

39 Vingerling JR, Dielemans I, Hofman A, Grobbee DE, Hijmering M, Kramer CF et al. The prevalence of agerelated maculopathy in the Rotterdam Study. Ophthalmology 1995; 102: 205-210.

40 Moss SE, Klein R, Meuer MB, Klein BE. The association of iris color with eye disease in diabetes. Ophthalmology 1987; 94: 1226-1231.

41 Frank RN, Puklin JE, Stock C, Canter LA. Race, iris color, and age-related macular degeneration. Trans Am Ophthalmol Soc 2000; 98: 109-115.

42 Mitchell P, Smith W, Wang JJ. Iris color, skin sun sensitivity, and age-related maculopathy. The Blue Mountains Eye Study. Ophthalmology 1998; 105: 1359-1363.

43 Holz FG, Piguet B, Minasian DC, Bird AC, Weale RA. Decreasing stromal iris pigmentation as a risk factor for age-related macular degeneration. Am J Ophthalmol 1994; 117: 19-23.

44 Klaver CC, Kliffen M, van Duijn CM, Hofman A, Cruts M, Grobbee DE et al. Genetic association of apolipoprotein E with age-related macular degeneration. Am J Hum Genet 1998; 63: 200-206.

45 Souied EH, Benlian P, Amouyel P, Feingold J, Lagarde JP, Munnich A et al. The epsilon4 allele of the apolipoprotein $\mathrm{E}$ gene as a potential protective factor for exudative age-related macular degeneration. Am J Ophthalmol 1998; 125: 353-359. 
46 Sarks SH. Ageing and degeneration in the macular region: a clinico-pathological study. Br J Ophthalmol 1976; 60: 324-341.

47 Green WR, Key SN. Senile macular degeneration: a histopathological study. Trans Am Ophthalmol Soc 1977; 75: 180-250.

48 Ramrattan RS, van der Schaft TL, Mooy CM, de Bruijn WC, Mulder PG, de Jong PT. Morphometric analysis of Bruch's membrane, the choriocapillaris, and the choroid in aging. Invest Ophthalmol Vis Sci 1994; 35: 2857-2864.

49 Okubo A, Rosa RH, Bunce KV, Alexander RA, Fan JT, Bird $\mathrm{AC}$ et al. The relationships between age changes in retinal pigment epithelium and Bruch's membrane. Invest Ophthalmol Vis Sci 1999; 40: 443-449.

50 Curcio CA, Medeiros NE, Millican CL. Photoreceptor loss in age-related macular degeneration. Invest Ophthalmol Vis Sci 1996; 37: 1236-1249.

51 Katz ML, Norberg M. Influence of dietary vitamin A on autofluorescence of leupeptin-induced inclusions in the retinal pigment epithelium. Exp Eye Res 1992; 54: 239-246.

52 von Rückmann A, Fitzke FW, Bird AC. Distribution of fundus autofluorescence with a scanning laser ophthalmoscope. Br J Ophthalmol 1995; 79: 407-412.

53 Delori FC, Dorey CK, Staurenghi G, Arend O, Goger DG, Weiter JJ. In vivo fluorescence of the ocular fundus exhibits retinal pigment epithelial lipofuscin characteristics. Invest Ophthalmol Vis Sci 1995; 36: 718-729.

54 Lois N, Coco R, Hopkins J, Owens SL, Fitzke FW, Bird AC. Fundus autofluorescence in patients with age-related macular degeneration and high risk characteristics. Am J Ophthalmol 2002; 133: 341-349.

55 Okubo A, Sameshima M, Unoki K, Uehara F, Bird AC. Ultrastructural changes associated with accumulation of inclusion bodies in rat retinal pigment epithelium. Invest Ophthalmol Vis Sci 2000; 41: 4305-4312.

56 Wiegand RD, Koutz CA, Stinson AM, Anderson RE. Conservation of docosahexaenoic acid in rod outer segments of rat retina during n-3 and n- 6 fatty acid deficiency. J Neurochem 1991; 57: 1690-1699.

57 Stinson AM, Wiegand RD, Anderson RE. Recycling of docosahexaenoic acid in rat retinas during n-3 fatty acid deficiency. J Lipid Res 1991; 32: 2009-2017.

58 Bird AC, Marshall J. Retinal pigment epithelial detachments in the elderly. Trans Ophthalmol Soc UK 1986; 105: 674-682.

59 Tsuboi S. Measurement of the volume flow and hydraulic conductivity across the isolated dog retinal pigment epithelium. Invest Ophthalmol Vis Sci 1987; 28: 1776-1782.

60 Pauleikhoff D, Harper CA, Marshall J, Bird AC. Aging changes in Bruch's membrane: a histochemical and morphological study. Ophthalmology 1990; 97: 171-178.

61 Sheraidah G, Steinmetz R, Maguire J, Pauleikhoff D, Marshall J, Bird A. Correlation between lipids extracted from Bruch's membrane and age. Ophthalmology 1993; 100: 47-51.

62 Moore DJ, Hussain AA, Marshall J. Age related variation in the hydraulic conductivity of Bruch's membrane. Invest Ophthalmol Vis Sci 1995; 36: 1290-1297.

63 Starita C, Hussain AA, Patmore A, Marshall J. Localization of the site of major resistance to fluid transport in Bruch's membrane. Invest Ophthalmol Vis Sci 1997; 38: 762-767.

64 Pauleikhoff D, Zuels S, Sheraidah G, Marshall J, Wessing A, Bird AC. Correlation between biochemical composition and fluorescein binding of deposits in Bruch's membrane. Ophthalmology 1992; 99: 1548-1553.
65 Chuang EL, Bird AC: Bilaterality of tears of the retinal pigment epithelium. Br J Ophthalmol 1988; 72: 918-920.

66 Chuang EL, Bird AC. The pathogenesis of tears of the retinal pigment epithelium. Am J Ophthalmol 1988; 105: 185-190.

67 Pauleikhoff D, Barondes MJ, Minassian D, Chisholm IH, Bird AC. Drusen as a risk factor in age related macular disease. Am J Ophthalmol 1990; 109: 38-43.

68 Hoskin A, Sehmi K, Bird AC. Sorby's pseudo-inflammatory macular dystrophy. Br J Ophthalmol 1981; 65: 859-865.

69 Capon M, Polkinghorne PJ, Bird AC. Sorsby's pseudoinflammatory dystrophy - Sorsby's fundus dystrophy. Eye 1988; 2: 114-122.

70 Polkinghorne PJ, Capon MR, Berninger TA, Lyness AL, Sehmi K, Bird AC. Sorsby's fundus dystrophy: a clinical study. Ophthalmology 1989; 96: 1763-1768.

71 Capon MRC, Marshall J, Kraft JI, Alexander RA, Hiscott PS, Bird AC. Sorsby's fundus dystrophy: a light and electron microscopic study. Ophthalmology 1989; 96: 1769-1777.

72 Pauleikhoff D, Chen JC, Chisholm IH, Bird AC. Choroidal perfusion abnormalities in age related macular disease. Am J Ophthalmol 1990; 109: 211-217.

73 Sarks SH. Changes in the region of the choriocapillaris in aging and degeneration. 23rd Concilium Ophthalmologists, Kyoto, 1978, pp 228-238.

74 Sarks SH, Sarks J, Killingsworth C. Evolution of geographic atrophy of the retinal pigment epithelium. Eye 1988; 2: 552-577.

75 Tso MOM. Pathogenetic factors of aging macular degeneration. Ophthalmology 1985; 92: 628-635.

76 Chen JC, Fitzke FW, Pauleikhoff D, Bird AC. Poor choroidal perfusion is a cause of visual morbidity in agerelated macular degeneration. Invest Ophthalmol Vis Sci 1992; 33: 334-340.

77 Meves H. Die pathologisch-anatomischen gefassveranderungen des auges bie der beningen und malingen nephrosklerose. Graefes Arch Ophthalmol 1948; 168: 287.

78 Friedman E, Smith TR, Kuwabara T. Senile choroidal vascular patterns and drusen. Arch Ophthalmol 1963; 69: 220-230.

79 Friedman E, Smith TR, Kuwabara T, Beyer CK. Choroidal vascular patterns in hypertension. Arch Ophthalmol 1964; 71: $842-850$

80 Korte GE, Repucci V, Henkind P. RPE destruction causes choriocapillary atrophy. Invest Ophthalmol Vis Sci 1984; 25: 1135-1145.

81 Glaser BM, Campochiaro PA, Davies JL, Sato M. Retinal pigment epithelial cells release an inhibitor of neovascularization. Arch Ophthalmol 1985; 103: 1870-1875.

82 Bok D. Retinal photoreceptor-pigment epithelium interactions. Invest Ophthalmol Vis Sci 1985; 26: 1659-1694.

83 Jacobson SG, Cideciyan AV, Regunath G, Rodriguez FJ Vandenburgh K, Sheffield VC et al. Night blindness in Sorsby's fundus dystrophy reversed by vitamin A. Nat Genet 1995; 11: 27-32.

84 Kiligsworth MC, Sarks JP, Sarks SH. Macrophages related to Bruch's membrane in age-related macular degeneration. Eye 1990; 4: 613-621.

85 Penfold PL, Madigan MC, Gillies MC, Provis JM. Immunological and aetiological aspects of macular degeneration. Prog Retinal Eye Res 2001; 20: 385-414. 
86 Anderson DH, Mullins RF, Hageman GS, Johnson LV. A role for local inflammation in the formation of drusen in the aging eye. Am J Ophthalmol 2002; 134: 411-431.

87 Hageman GS, Luthert PJ, Victor Chong NH, Johnson LV, Anderson DH, Mullins RF. An integrated hypothesis that considers drusen as biomarkers of immune-mediated processes at the RPE-Bruch's membrane interface in aging and age-related macular degeneration. Prog Retinal Eye Res 2001; 20: 705-732.

88 Mullins RF, Stephenson R, Russel SR, Anderson DH, Hageman GS. Drusen associated with aging and agerelated macular degeneration contain proteins common to extracellular deposits associated with atherosclerosis, elastosis, amyloidosis, and dense deposit disease. FASEB J 2000; 14: 835-846.

89 Ross R. Atherosclerosis - an inflammatory disease. $N$ Engl J Med 1999; 340: 115-126.

90 Libby P, Rodker PM, Maseri A. Inflammation and atherosclerosis. Circulation 2002; 105: 1135-1143.

91 Dawson DW, Volpert OV, Gillis P, Crawford SE, Xu H, Benedict $\mathrm{W}$ et al. Pigment epithelium-derived factor: a potent inhibitor of angiogenesis. Science 1999; 285: 245-248.

92 Duh EJ, Yang HS, Suzuma I, Miyagi M, Youngman E, Mori $\mathrm{K}$ et al. Pigment epithelium-derived factor suppresses ischemia-induced retinal neovascularization and VEGFinduced migration and growth. Invest Ophthalmol Vis Sci 2002; 43: 821-829.

93 Takagi H, King GL, Aiello LP. Identification and characterization of vascular endothelial growth factor receptor (Flt) in bovine retinal pericytes. Diabetes 1996; 45 1016-1023.

94 Tombran-Tink J, Shivaram SM, Chader GJ, Johnson LV, Bok D. Expression, secretion, and age-related downregulation of pigment epithelium-derived factor, a serpin with neurotrophic activity. J Neurosci 1995; 15: 4992-5003.

95 Xiao M, McLeod D, Cranley J, Williams G, Boulton M. Growth factor staining patterns in the pig retina following retinal laser photocoagulation. Br J Ophthalmol 1999; 83: 728-736.

96 Boyd SR, Zachary I, Chakravarthy U, Allen GJ, Wisdom GB, Cree IA et al. Correlation of increased vascular endothelial growth factor with neovascularization and permeability in ischemic central vein occlusion. Arch Ophthalmol 2002; 120: 1644-1650.

97 Ogata N, Nishikawa M, Nishimura T, Mitsuma Y, Matsumura M. Unbalanced vitreous levels of pigment epithelium-derived factor and vascular endothelial growth factor in diabetic retinopathy. Am J Ophthalmol 2002; 134: 348-353.

98 Ishibashi T, Hata Y, Yoshikawa H, Nakagawa K, Sueishi K, Inomata $\mathrm{H}$. Expression of vascular endothelial growth factor in experimental choroidal neovascularization. Graefes Arch Clin Exp Ophthalmol 1997; 235: 159-167.

99 Kliffen M, Sharma HS, Mooy CM, Kerkvliet S, de Jong PT. Increased expression of angiogenic growth factors in agerelated maculopathy. Br J Ophthalmol 1997; 81: 154-162.

100 Kvanta A, Algvere PV, Berglin L, Seregard S. Subfoveal fibrovascular membranes in age-related macular degeneration express vascular endothelial growth factor. Invest Ophthalmol Vis Sci 1996; 37: 1929-1934.

101 Garron LK. The ultrastructure of the retinal pigment epithelium with observations on the choriocapillaris and Bruch's membrane. Trans Am Ophthalmol Soc. 1963; 61: 545-588.
102 Leeson TS, Leeson CR. Choriocapillaris and lamina elastica (vitrea) of the rat eye. Brit J Ophthalmol 1967; 51: 599-615.

103 Matsusaka T. Undescribed endothelial processes of the choriocapillaris extending to the retinal pigment epithelium of the chick. Br J Ophthalmol 1968; 52: 887-892.

104 Yamamoto T, Yamashita H. Psuedopodia of choriocapillary endothelium. Jpn J Ophthalmol 1989; 33: 327-336.

105 Guymer RH, Hageman GS, Bird AC. Influence of laser photocoagulation on choroidal capillary cytoarchitecture. Br J Ophthalmol 2001; 85: 40-46.

106 Lander E, Kruglyak L. Genetic dissection of complex traits: guidelines for interpreting and reporting linkage results. Nat Genet 1995; 11: 241-247.

107 Hutchinson J, Tay W. Symmetrical central chorio-retinal disease occurring in senile persons. $R$ London Ophthalmol Hosp Rep 1875; 83: 275-285.

108 Barondes M, Pauleikhoff D, Chisholm IH, Minassian D, Bird AC. Bilaterality of drusen. Br J Ophthalmol 1990; 74: 180-182.

109 Allikmets R, Shroyer NF, Singh N, Seddon JM, Lewis RA, Bernstein PS et al. Mutation of the Stargardt disease gene (ABCR) in age-related macular degeneration. Science 1997; 277: 1805-1807.

110 Stone E M, Webster AR, Vandenburgh K, Streb LM, Hockey RR, Lotery AJ, Sheffield VC. Allelic variation in ABCR associated with Stargardt disease but not agerelated macular degeneration. Nat Genet 1998; 20: 328-329.

111 International ABCR Screening Consortium. Statistically significant association of sequence variants in the ABCR gene with age-related macular degeneration. Am J Hum Genet 2000; 67: 487-491.

112 Mares-Perlman JA, Brady WE, Klein R, Klein BE, Bowen P, Stacewicz-Sapuntzakis $\mathrm{M}$ et al. Serum antioxidants and age-related macular degeneration in a population-based case-control study. Arch Ophthalmol 1995; 113: 1518-1523.

113 Seddon JM, Ajani UA, Sperduto RD, Hiller R, Blair N, Burton TC et al. Dietary carotenoids, Vitamins A, C and E and advanced age related macular degeneration. JAMA 1994; 272: 1413-1420.

114 Klein R, Klein BEK, Linton KLP. Prevalence of age-related maculopathy. The Beaver-Dam Eye Study. Ophthalmology 1992; 99: 933-943.

115 Mitchell P, Smith W, Attebo K, Wang JJ. Prevalence of agerelated maculopathy in Australia. The Blue Mountains Eye Study. Ophthalmology 1995; 102: 1450-1460.

116 Klaver CC, Assink JJ, Vingerling JR, Hofman A, de Jong PT. Smoking is also associated with age-related macular degeneration in persons aged 85 years and older: the Rotterdam Study. Arch Ophthalmol. 1997; 115: 945.

117 Smith W, Assink J, Klein R, Mitchell P, Klaver CC, Klein BE et al. Risk factors for age-related macular degeneration: pooled findings from three continents. Ophthalmology 2001; 108: 697-704.

118 Sisodia SS, St George-Hyslop PH. gamma-Secretase, Notch, Abeta and Alzheimer's disease: where do the presenilins fit in? Nat Rev Neurosci 2002; 3: 281-290.

119 Weber BH, Vogt G, Pruett RC, Stohr H, Felbor U. Mutations in the tissue inhibitor of metalloproteinases-3 (TIMP3) in patients with Sorsby's fundus dystrophy. Nat Genet 1994; 8: 352-681.

120 Crabb JW, Miyagi M, Gu X, Shadrach K, West KA, Sakaguchi $\mathrm{H}$ et al. Drusen proteome analysis: an approach to the etiology of age-related macular degeneration. Proc Natl Acad Sci USA 2002; 99: 14682-14687. 